\title{
Chyloptysis with right middle lobe syndrome complicated postoperatively by chylothorax: An unusual cause of right middle lobe syndrome
}

\author{
Chamani Illamperuma MD DABIM FRCPC ${ }^{1}$, John Reid MD FRCPC DABSM ${ }^{1}$, Rani Kanthan MBBS MS FRCS FRCPC FCAP MMed ${ }^{2}$
}

\begin{abstract}
C Illamperuma, J Reid, R Kanthan. Chyloptysis with right middle lobe syndrome complicated postoperatively by chylothorax: An unusual cause of right middle lobe syndrome. Can Respir J 2009;16(2):e1-e2.

Chyloptysis, in the context of middle lobe syndrome, and chylothorax are rare clinical entities. They are reported in the medical literature mostly as case reports, but never together in the same patient. The present report describes the case of a 34-year-old woman who presented with chyloptysis associated with recurrent right middle lobe syndrome since she was 20 years of age, and eventually underwent right middle lobectomy. A few weeks postoperatively, she developed a right-sided chylothorax, which was refractory to medical therapy, and was successfully treated with thoracic duct ligation. She has been symptom-free for two years postsurgery.
\end{abstract}

Key Words: Chyloptysis; Chylothorax; Right middle lobe syndrome
Une chyloptysie accompagnant un syndrome du lobe moyen du poumon droit compliquée par un chylothorax après une opération : Une cause inhabituelle de syndrome du lobe moyen du poumon droit

La chyloptysie, en présence d'un syndrome du lobe moyen du poumon droit, et le chylothorax sont des manifestations cliniques rares. On les trouve surtout sous forme de rapports de cas dans les publications médicales, mais jamais de manière simultanée chez le même patient. Le présent rapport contient la description du cas d'une femme de 34 ans qui a présenté une chyloptysie associée à un syndrome récurrent du lobe moyen du poumon droit depuis l'âge de 20 ans et a fini par subir une lobectomie du lobe moyen du poumon droit. Quelques semaines après l'opération, elle a développé un chylothorax du côté droit, réfractaire à la pharmacothérapie, et a été traitée avec succès par ligature du canal thoracique. Deux ans après l'opération, elle demeurait sans symptômes.

\section{CASE PRESENTATION}

A 20-year-old lifetime nonsmoking Caucasian woman presented with a one-year history of intermittent dyspnea and cough productive of milky white sputum that had the consistency of soft cheese. Chest radiographs showed airspace disease in the right middle lobe, suggestive of right middle lobe syndrome (RMLS). There was no association with meals or with her menstrual cycle. Her medical history was unremarkable, and there was no history of trauma or surgery. Her only medication was oral contraceptives. Her father died of nonHodgkin's lymphoma; otherwise, her family history was negative. She worked as a medical receptionist. A physical examination revealed her to be healthy and well nourished with no abnormal findings. Routine laboratory evaluation was unremarkable. Serological and acid-fast bacilli sputum tests were negative. Spirometry was normal. The chest $\mathrm{x}$-ray revealed right middle and lower lobe collapse/consolidation (Figure 1). A computed tomography (CT) scan further demonstrated a small left-sided pleural effusion with no mediastinal adenopathy or underlying parenchymal abnormality. Flexible bronchoscopy was performed and bronchial alveolar lavage fluid had revealed a cholesterol level of $0.45 \mathrm{mmol} / \mathrm{L}$, triglyceride level of $6.35 \mathrm{mmol} / \mathrm{L}$ and 'heavy' chylomicron content.

The patient declined further investigations and was lost to follow-up for eight years, during which time her symptoms continued to recur every few months. There remained no association with her menstrual cycle and no change in symptoms during her two pregnancies. Each event caused her to miss work

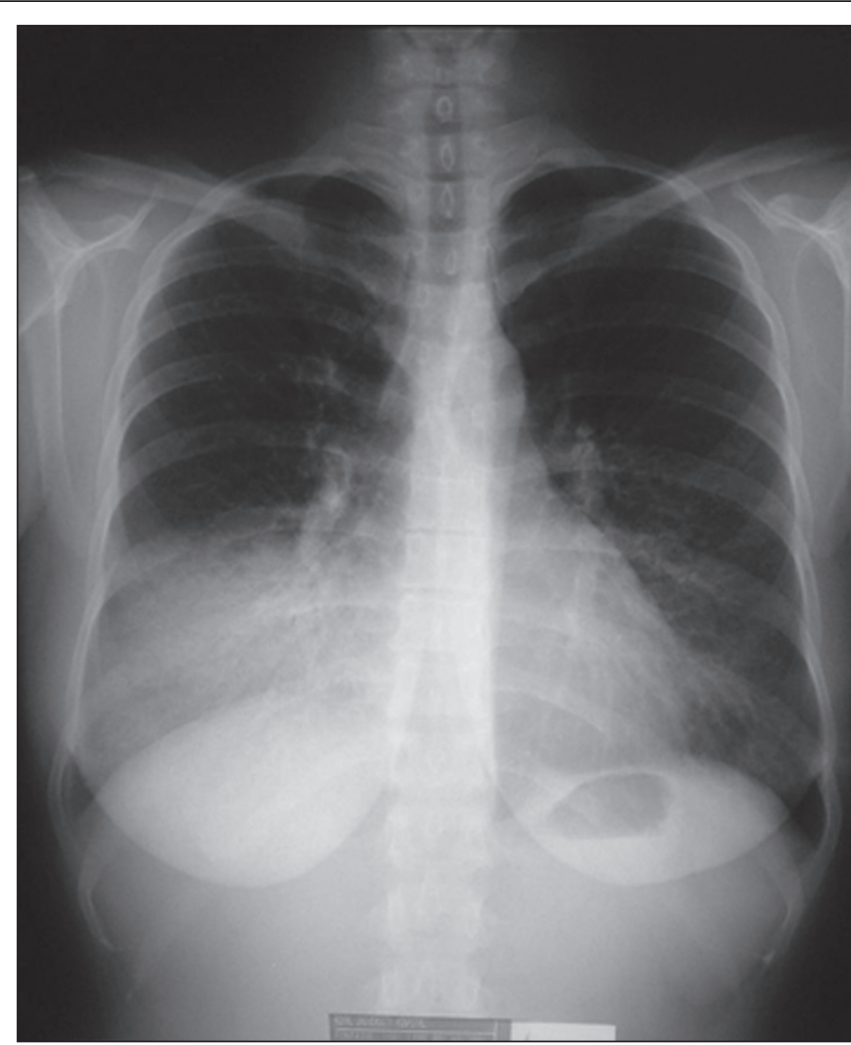

Figure 1) Posterior-anterior film showing collapse/consolidation of the right middle lobe

${ }^{1}$ Department of Respirology, Critical Care and Sleep Medicine; ${ }^{2}$ Department of Pathology, University of Saskatchewan, Saskatoon, Saskatchewan Correspondence: Dr John Reid, Department of Respirology, Critical Care and Sleep Medicine, University of Saskatchewan, 5th Floor, Ellis Hall,

103 Hospital Drive, Saskatoon, Saskatchewan. E-mail reidj@skyway.usask.ca 


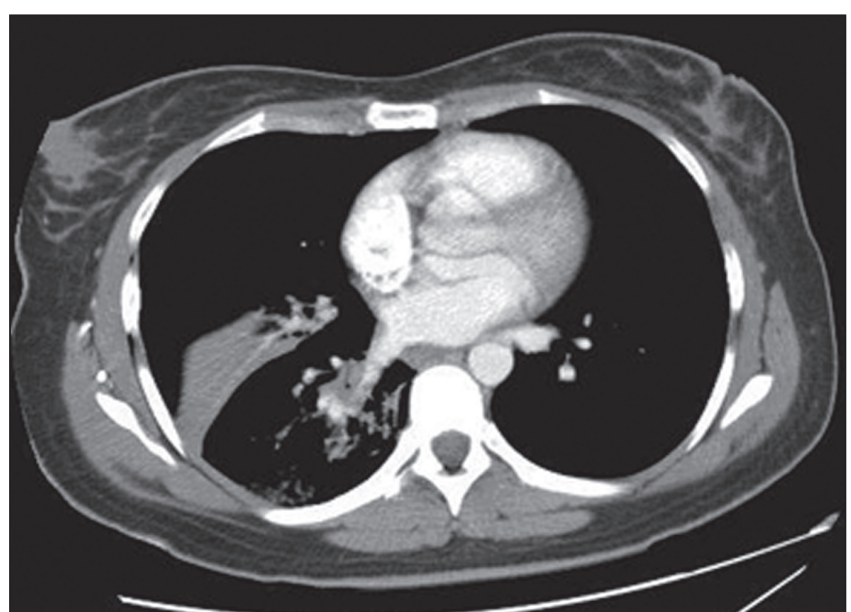

Figure 2) Collapse/consolidation of the right middle lobe with associated airspace disease spilling over to the right lower lobe, as seen on chest computed tomography

for one or two days, but she never required hospitalization. She remained healthy with no problems other than the presenting complaint. By 2003, her events were becoming more frequent and severe, and she agreed to be further investigated. A CT scan during an event again demonstrated collapse/consolidation of the right middle lobe (Figure 2). Repeat bronchoscopy revealed normal tracheal bronchial anatomy and thick creamy secretions in the right lower lobe and particularly the right middle lobe. Bronchial alveolar lavage findings were similar to those demonstrated eight years previously. Transbronchial biopsy was nondiagnostic. She was referred to a thoracic surgeon who performed an open thoracotomy with right middle lobe resection in August 2005. No obvious pathology in the lobe or in the node surrounding the middle lobe bronchus was seen at the time of resection. The specimen sent for pathology showed only chronic inflammation, consistent with RMLS.

Five weeks postoperatively, the patient presented with worsening dyspnea with a large right-sided chylothorax. Thoracentesis fluid revealed lipid-laden macrophages. The patient was treated with octreotide, a fat-free diet and chest tube drainage of the pleural effusion. Unfortunately, pleural fluid re-accumulated and a repeat thoracotomy was performed for supradiaphragmatic ligation of the thoracic duct and pleural abrasion. Her postoperative course was uneventful, and she remains asymptomatic more than two years later.

\section{DISCUSSION}

Chyloptysis is expectoration of sputum rich in chyle (high triglyceride and chylomicron content) and is typically described as 'milky white' sputum. Abnormal transportation of chyle in the chest may manifest as chyloptysis with or without bronchial cast formation, chylothorax and chylopericardium. The recognition of the chylous nature of the sputum is requisite for accurate diagnosis, especially if chyloptysis is not accompanied by chylous pleural effusion, because the symptoms and radiographic findings are nonspecific (1). The pulmonary lymphatics empty into the right and left bronchomediastinal trunks, which then empty into either the junctions of the subclavian and internal jugular veins or into the thoracic duct. Two mechanisms are postulated for the etiology of chyloptysis: abnormal communication between the bronchial tree and the lymphatic channels (we suspect that this is the relevant problem in our patient), and bronchopleural fistula in the context of a chylous pleural effusion (1). Causes include acquired or congenital lymphangiectasis, lymphangiomatosis (2), thoracic radiation or malignancy, yellow nail syndrome and Behçet's disease $(1,3)$. Chylothorax is usually caused by traumatic or inadvertent surgical disruption of the thoracic duct (4).

Our patient presented with recurrent chyloptysis and RMLS. The cause is almost certainly aberrant lymphatic drainage, which may have complicated her right middle lobe resection and resulted in postoperative chylothorax. Pulmonary lymphangiography or CT lymphangiography can be used to evaluate the thoracic lymphatics and demonstrate lymphatic efflux into the bronchi (1). Lymphangiography could not only have confirmed the diagnosis but by delineating the anatomical abnormality, it may have also assisted in resection planning and thereby reduced the risk of postoperative bile leak. Unfortunately, the radiology department at the University of Saskatchewan (Saskatoon, Saskatchewan) was unable to perform thoracic lymphangiography.

Management of both chyloptysis and chylothorax can be medical or surgical. Medical management described in case reports for chyloptysis include observation (2), and low-fat diet with medium chain triglyceride supplementation to reduce the flow of lymph from the small bowel $(1,5)$. Recent literature suggests that octreotide is effective in cases when other medical therapies have failed (6). Unfortunately, treatment with octreotide was unsuccessful in our patient. Surgery is recommended for medical treatment failure $(5,7)$ and was curative for our patient. Surgical techniques include right supradiaphragmatic thoracic duct ligation (the procedure used in our patient), pleuroperitoneal shunting, thoracoscopic talc pleurodesis and parietal pleurectomy. In retrospect, thoracic duct ligation at the time of initial surgery would have been advisable in our patient, particularly without lymphagiographic information to guide a more targeted resection.

Chyloptysis and chylothorax are uncommon phenomena. Chyloptysis is most commonly due to aberrant or obstructed lymphatic drainage, and chylothorax is usually the result of chest trauma, thoracic surgery or maligancy. Our patient is interesting because she presented with recurrent chyloptysis for 10 years with an associated RMLS, despite being young and otherwise healthy with no known predisposing factors. Surgeries for right middle lobectomy, and ultimately, thoracic duct ligation were curative.

\section{REFERENCES}

1. Lim KG, Rosenow EC, Staats B, Couture C, Morgenthaler TI. Chyloptysis in adults: Presentation recognition and differential diagnosis. Chest 2004;125:336-40.

2. Wetherill SF, Davies AL, Mayock RL. Chyloptysis. Am J Med 1990;88:437-8.

3. Ababoglu O, Osma E, Ucan ES, et al. Behcet's disease with pulmonary involvement, superior vena cava syndrome, chyloptysis and chylous ascites. Respir Med. 1996:90:429-31.

4. Le Pimpee-Barthes F, Badia A, Febvre M, Legman P, Riquet M. Chylous reflux into localized pulmonary lymphangiectasis. Ann Thorac Surg 2002;74:575-8.

5. Robotin MC, Edis BD, Weintraub RG, et al. Heart transplantation for chyloptysis after Fontan operation. Ann Thorac Surg 1995;59:1570-1.

6. Paget-Brown A, Kattwinkel J, Rodgers BM, Michalsky MP. The use of octreotide to treat congenital chylothorax. J Pediatr Surg 2006;41:845-7.

7. Valentine VG, Raffin TA. The management of chylothorax. Chest 1992;102:586-91. 


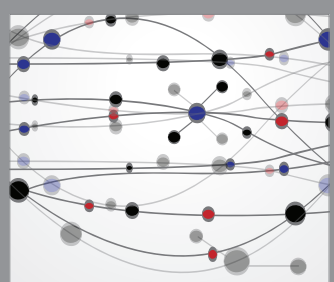

The Scientific World Journal
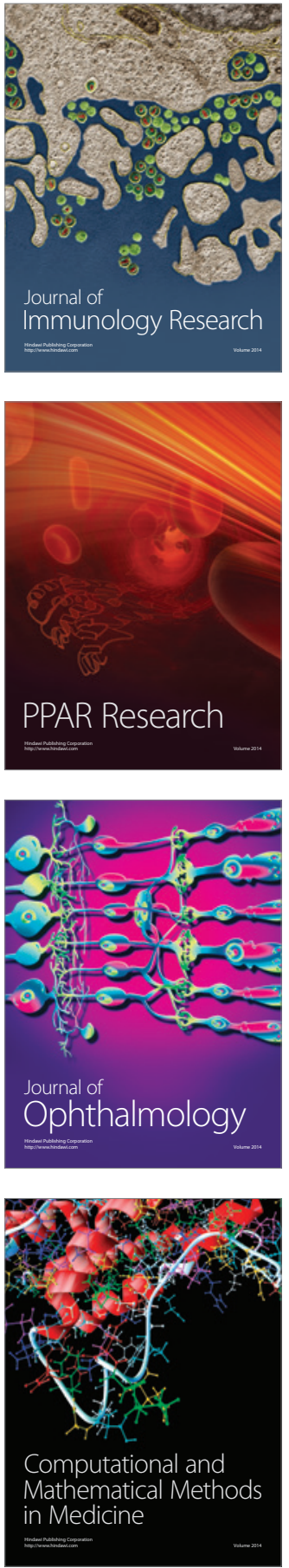

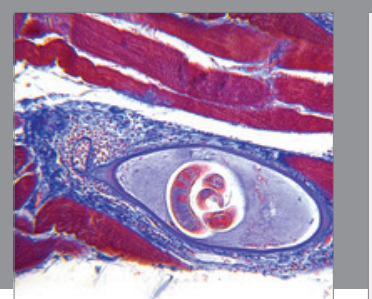

Gastroenterology Research and Practice

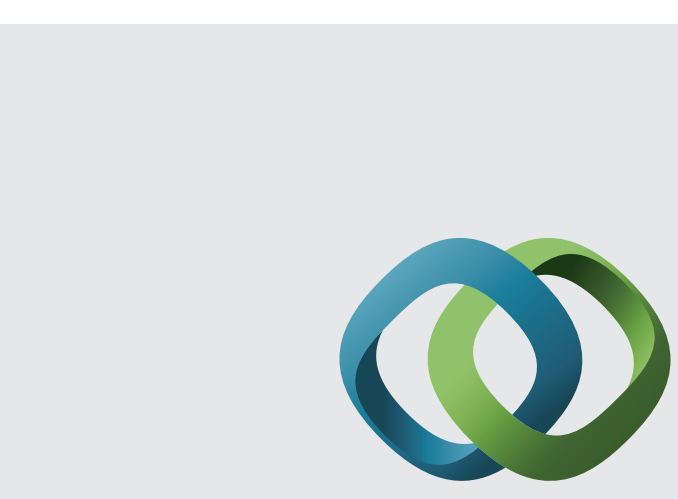

\section{Hindawi}

Submit your manuscripts at

http://www.hindawi.com
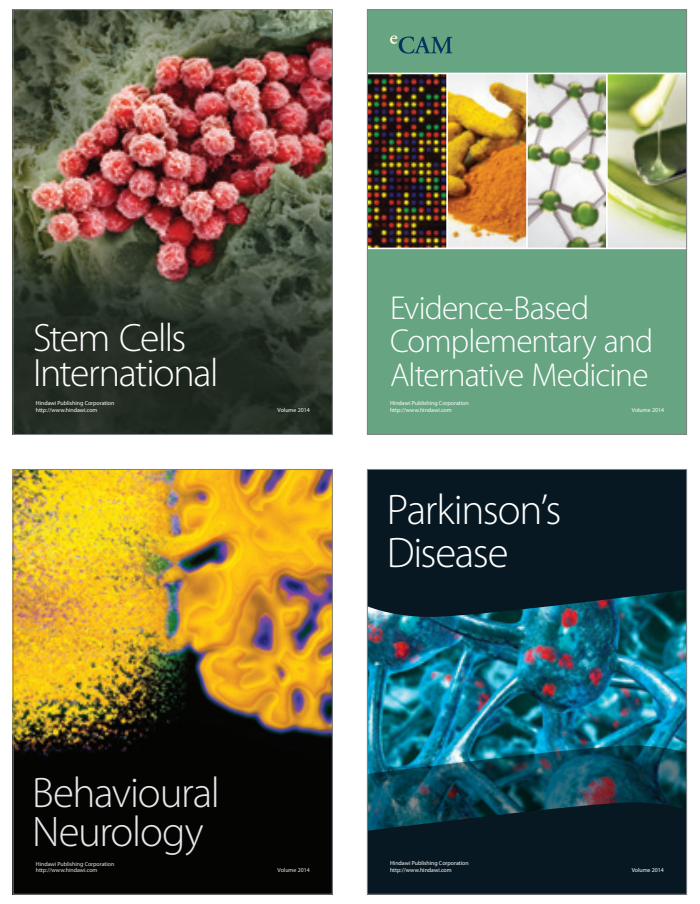
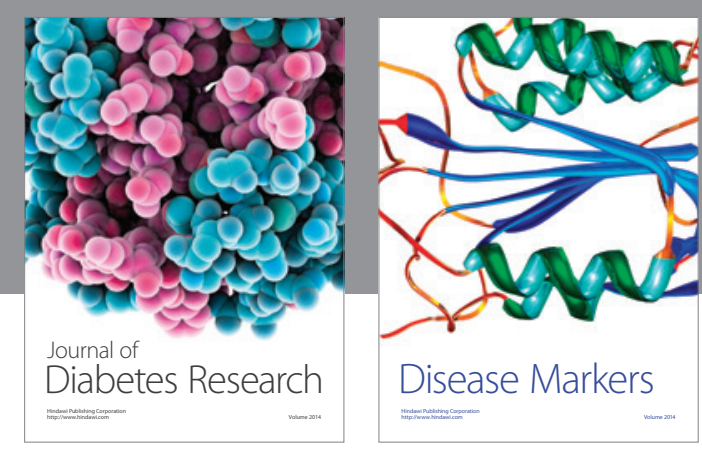

Disease Markers
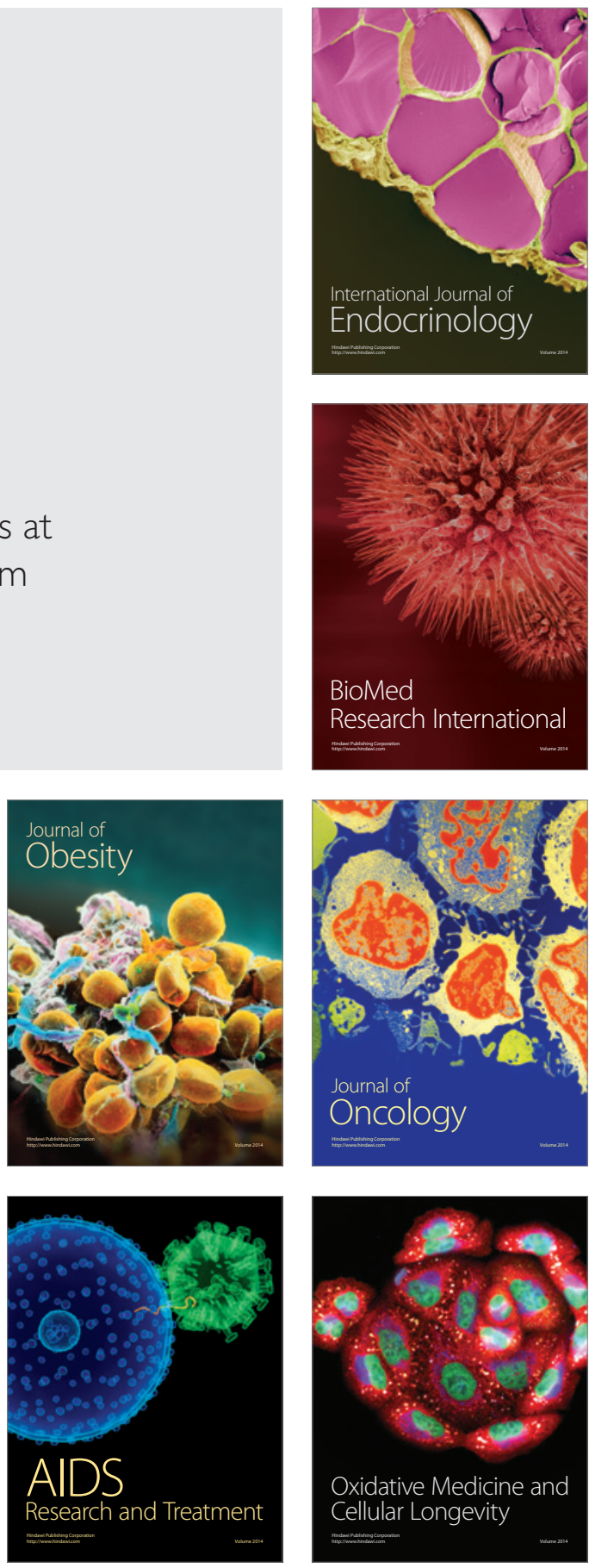